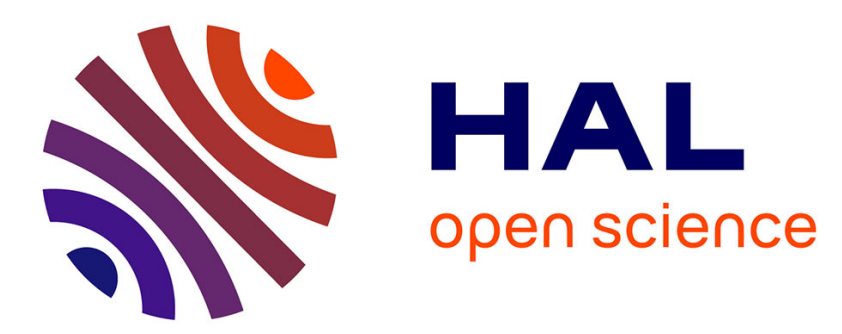

\title{
Electro-optical properties of twisted nematic liquid crystals: An application to voltage controllable color formation
}

\author{
H. Mada, S. Kobayashi
}

\section{- To cite this version:}

H. Mada, S. Kobayashi. Electro-optical properties of twisted nematic liquid crystals: An application to voltage controllable color formation. Revue de Physique Appliquée, 1975, 10 (3), pp.147-151. 10.1051/rphysap:01975001003014700 . jpa-00243894

\section{HAL Id: jpa-00243894 https://hal.science/jpa-00243894}

Submitted on 1 Jan 1975

HAL is a multi-disciplinary open access archive for the deposit and dissemination of scientific research documents, whether they are published or not. The documents may come from teaching and research institutions in France or abroad, or from public or private research centers.
L'archive ouverte pluridisciplinaire HAL, est destinée au dépôt et à la diffusion de documents scientifiques de niveau recherche, publiés ou non, émanant des établissements d'enseignement et de recherche français ou étrangers, des laboratoires publics ou privés. 


\title{
ELECTRO-OPTICAL PROPERTIES OF TWISTED NEMATIC LIQUID CRYSTALS : AN APPLICATION TO VOLTAGE CONTROLLABLE COLOR FORMATION $\left({ }^{*}\right)\left({ }^{* *}\right)$
}

\author{
H. MADA and S. KOBAYASHI \\ Department of Electronic Engineering, \\ Faculty of Technology, Tokyo University of Agriculture and Technology, \\ Koganei, Tokyo 184, Japan \\ (Reçu le 30 juillet 1974, révisé le 9 décembre 1974, accepté le 16 janvier 1975)
}

\begin{abstract}
Résumé. - Nous avons recherché les conditions optimum de la formation des couleurs par contrôle de la tension appliquée à des cristaux liquides nématiques ayant une anisotropie diélectrique positive et un alignement homogène. Nous avons trouvé que les conditions optimum étaient réalisées en choisissant un angle de déviation pour les cristaux nématiques liquides égal à zéro et en leur adjoignant des polariseurs croisés ou parallèles, à $45^{\circ}$ par rapport aux lignes directrices des molécules des cristaux liquides. Il existe plusieurs conditions possibles pour la formation des couleurs par contrôle de la tension. Les polariseurs utilisés pour les recherches étaient des polariseurs sans effet colorant. Nous avons ensuite relevé les spectres de la lumière transmise après mise sous tension. Nous avons déterminé la largeur des spectres à partir des biréfringences efficaces; nous avons ensuite comparé ces valeurs avec celles obtenues par une méthode indépendante. Une bonne corrélation entre les résultats montre la validité du modèle adopté pour ce travail.
\end{abstract}

\begin{abstract}
Optimum conditions for the voltage controllable color formation (VCCF) using nematic liquid crystals with a positive dielectric anisotropy which have homogeneous alignment were studied. It is shown that the optimum condition is realized by choosing the twisting angle of the nematic liquid crystals equal to zero and by setting parallel or crossed polarizers at $45^{\circ}$ relative to the directors of the molecules of the liquid crystals. There are several alternative conditions for VCCF. The polarizers used in the research were neutral color polarizers. Spectra of the transmitted light under the application of the voltages were obtained. From the effective birefringence, the widths of the spectra were determined. These values are compared with those which were determined by an independent method. Good agreement between them shows a validity of the model adopted in this work.
\end{abstract}

1. Introduction. - A number of variable color display devices that use nematic liquid crystals have been reported [1]-[7]. Among them, Sheffer [5] and Kobayashi et al. [6] showed the possibility of the multicolor display devices which have comparatively high contrast using external dichroic polarizers $[5,6]$ or external optical retardation plates [5] combined with a twisted nematic structure [8]. Schiekel and Fahrenschon [2] reported a voltage controllable color formation (VCCF) using nematic liquid crystals with a negative dielectric anisotropy combined with a couple of neutral color polarizers.

In the previous papers, the present authors and their collaborators [9] reported some preliminary works on the VCCF with twisted nematic liquid crystals with a

(*) Parts of this paper were presented at the Vth International Liquid Crystal Conference in Stockholm, June 17-21, 1974.

$\left({ }^{* *}\right)$ Work is partially supported by a research budget of the Inst. Physical and Chemical Res., Saitama, Japan. positive dielectric anisotropy. In this paper, a more detailed description of the experimental research on some electro-optical properties of homogeneously aligned (molecules are parallel to the electrodes) nematic liquid crystals with a positive dielectric anisotropy is given including the cases where the twisting angle is not always equal to $90^{\circ}$ and where the angle between the direction of polarizer and the direction of molecules at the surface of the first electrode is not zero. Also the optimum condition for a voltage controllable color formation and its spectral analysis is described.

2. Analytical considerations. - First, an expression for the optical transmission is derived for a panel in which both the directions of a couple of polarizers and the twisting angle of nematic liquid crystals are not restricted to a special direction or a value.

Figure 1 shows how the polarizers and the molecules of liquid crystals are arranged ; the notations, $\psi_{0}, \psi$, and $\Psi$ stand for the angles between polarizer and the 


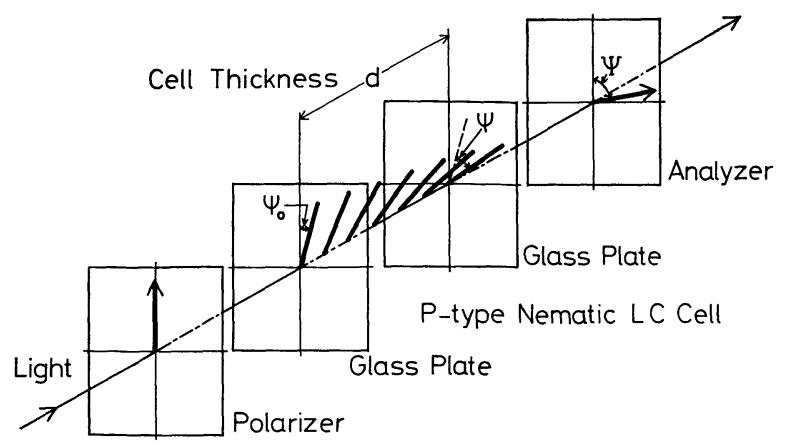

Fig. 1. - Arrangement of the polarizer, analyzer, and twisted nematic liquid crystal cell. Notation $\psi_{0}, \psi$, and $\Psi$ are the angle between polarizer and the directors of liquid crystals at the first electrode, the rotatory power (the twisting angle at zero field), and the angle between polarizer and analyzer, respectively.

directors of molecules which are aligned homogeneously on the surface of the first electrode, the magnitude of the rotatory power $\left({ }^{1}\right)$ of nematic liquid crystals, and the angle between polarizer and analyser, respectively.

The light beam is transmitted from left to right through the panel. In figure 2, the same notations are illustrated by projecting the panel on a plane normal to the direction of the incident light. Suffix o and e are stand for the ordinary and extraordinary rays, respectively.

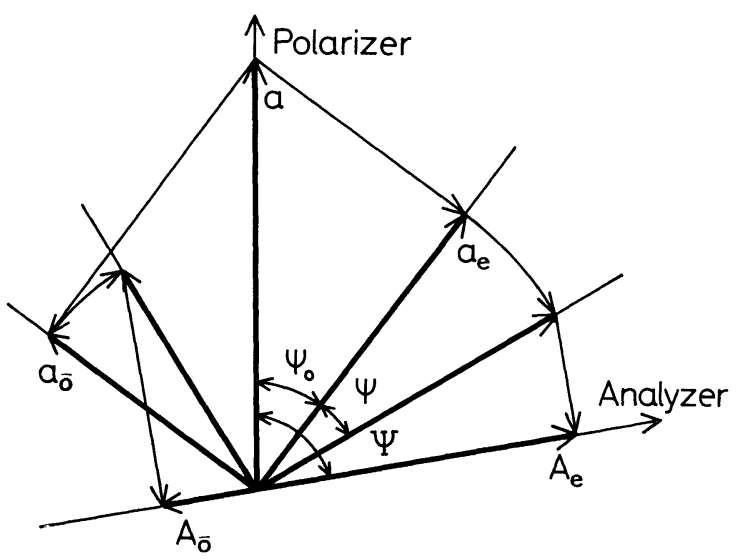

Fig. 2. - Relations of angles between polarizer, liquid crystal molecules, and analyzer ; the figure is that which is projected on a plane with its normal parallel to the direction of incident light. Notations are the same as illustrated in figure 1.

By a simple calculation [10], one derives a formula for the optical transmission $T$ for a system shown in figures 1 and 2 as follows :

$$
\begin{aligned}
& T \propto \cos ^{2}(\Psi-\psi)+ \\
& \quad+\sin 2 \psi_{0} \sin 2\left(\Psi-\left(\psi_{0}+\psi\right)\right) \sin ^{2}\left(\frac{\delta}{2}\right)
\end{aligned}
$$

(1) The quantity $\psi$ is also the twisting angle of nematic liquid crystals under the condition of zero field. where, $\delta$ is the phase difference between the ordinary and the extraordinary rays, and is given by $\delta=2 \pi \Delta n d / \lambda$, where $\Delta n, d$, and $\lambda$ are the effective birefringence, the thickness of the layer of nematic liquid crystals, and the wavelength of the incident light, respectively.

Both the magnitudes of $\psi$ and $\delta$ decrease as the applied electric field is increased in the region of above the threshold voltage; these are the origins of the electro-optical effects in the twisted nematic panel or homogeneously aligned nematic liquid crystal cell. Theoretically, as the rotatory power $\psi$ depends on the electric field, it is derived from a theory formulated by Leslie [11] and de Vries [12]. Numerical relationship between $\psi$ and electric field is not given here. However, some electro-optical properties will be derived from eq. (1).

Now, we will look for the optimum condition for voltage controllable color formation (VCCF). By differentiating eq. (1) with $\psi_{0}, \psi$, and $\Psi$, respectively, one derives the optimum condition for VCCF as follows :

$$
\begin{gathered}
\Psi-\psi=m(\pi / 2) \text { and } \psi_{0}=\pi / 4, \\
m=0, \pm 1, \pm 2, \ldots
\end{gathered}
$$

It is deduced from eq. (2) that the most distinct VCCF is realized by setting $\psi=0$ (zero twisting angle), $\Psi=0$ or $90^{\circ}$, and $\psi_{0}=45^{\circ}$. Phenomenologically, the meaning of the optimum condition for VCCF is that under this condition, the most distinct and purest voltage dependent color formation is realized as will be illustrated later.

It is notable that the traditional twisted nematic device corresponds to the case where $\psi=90$ (the twisting angle is $\left.90^{\circ}\right) \Psi=0$ or $90^{\circ}$, and $\psi_{0}=0$. In this case no VCCF is expected for normally incident light and that even in the case where the twisting angle $\psi$ is $90^{\circ}$ the occurrence of VCCF is expected by changing the value of $\psi_{0}$. Generally, more or less, the VCCF effect is expected otherwise the second term in eq. (1) is not zero.

Then, the spectral width of VCCF is considered as shown experimentally later, the spectra of transmitted lights through the panels shown in figures 1 and 2 have some peak wavelengths $\lambda_{\max }$ and finite widths. From eq. (1) one can derive the following expression for the condition of maximum and half transmission.

$$
\frac{\pi \Delta n_{\max } d}{\lambda_{\max }}=\frac{\pi}{2}(2 m-1)
$$

and

$$
\frac{\pi \Delta n_{1 / 2} d}{\lambda_{1 / 2}}=\frac{\pi}{4}\{2(2 m-1) \pm 1\} .
$$

Eliminating $m$ from eqs. (3) and (4), one finds

$$
\frac{\Delta n_{1 / 2}}{\lambda_{1 / 2}}=\frac{\Delta n_{\max }}{\lambda_{\max }} \pm \frac{1}{4 d}=A_{ \pm} .
$$


In the case that $\Delta n$ is not dependent on wavelength, but on applied voltage, one can deduce the following equation for the half width $W_{1 / 2}$ :

$W_{1 / 2}=\frac{8 \Delta n d \lambda_{\max }^{2}}{16 \Delta n^{2} d^{2}-\lambda_{\max }^{2}} \quad$ (for constant $\left.\Delta n\right)$.

On the other hand, assuming that the $\Delta n$ depend on wavelength as follows :

$\Delta n=a+\frac{b}{\lambda^{2}}+\frac{c}{\lambda^{4}} \quad$ (Cauch's dispersion formula)

then, the half width $W_{1 / 2}$ can be expressed by the following equation

$$
W_{1 / 2}=|\alpha-\beta|
$$

where $\alpha$ and $\beta$ are the real roots corresponding to $\mathrm{A}_{+}$ and $\mathrm{A}_{-}$in the following equation :

$$
A_{ \pm} \lambda_{1 / 2}^{5}-a \lambda_{1 / 2}^{4}-b \lambda_{1 / 2}^{2}-c=0
$$

where $a, b$ and $c$ are the same coefficients used in eq. (7).

3. Experimental results and discussions. - Both the optical transmission for monochromatic lights versus applied voltages and the spectral transmission were measured on the cells in which a $4: 1$ MBBA and BBCA mixture was disposed. The cells were driven by an ac field at $5 \mathrm{kHz}$ and their temperature was regulated and controlled by a thermoelement device. A couple of the neutral-color polarizers were used throughout the experiments.

The measurements were performed on the three different cells ; Table I shows the twisting angles, other angular relations, and the thickness of liquid crystals fo the cells.

\section{TABLE I}

\begin{tabular}{|c|c|c|c|c|}
\hline Configuration & $\begin{array}{c}\Psi \\
\text { (deg.) }\end{array}$ & $\begin{array}{c}\Psi_{0} \\
\text { (deg.) }\end{array}$ & $\begin{array}{c}\Psi \\
\text { (deg.) }\end{array}$ & $\begin{array}{c}\mathrm{d} \\
(\mu \mathrm{m} \text { ) }\end{array}$ \\
\hline Cell I & 90 & 0 & 90 & 6 \\
\hline Cell II & 90 & 45 & 90 & 9 \\
\hline Cell III & 0 & 45 & 90 & 9 \\
\hline
\end{tabular}

Figure 3 shows a result of the measurement of the transmission versus voltage on Cell I (normal TN cell, $\psi=90^{\circ}, \psi_{0}=0$, and $\Psi=90^{\circ}$ ) for three monochromatic lights (red $(650 \mathrm{~nm})$, green $(530 \mathrm{~nm})$, and blue $(460 \mathrm{~nm})$ ) which were generated with glass filters. It is clear from figure 3 that the characteristics of the transmission are almost independent of wavelength. This behavior agrees with the theoretical consideration

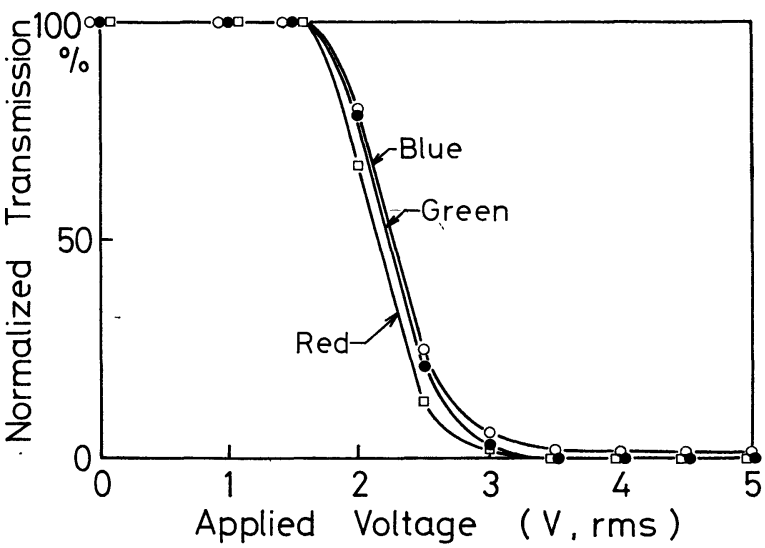

FIG. 3. - Normalized transmission of three different monochromatic light versus applied electric field at $5 \mathrm{kHz}$ (r. m. s.). The cell was a twisted nematic cell (twisting angle $\psi$ was $90^{\circ}$ ), a couple of crossed polarizers $\left(\Psi=90^{\circ}\right)$ was set so as $\psi_{0}$ to be zero. Material was a mixture of MBBA and BBCA by $4: 1$. Thickness of the cell was $6 \mu \mathrm{m}$.

given in the previous section. On the other hand, remarkable dependence of the transmission on the wavelength was observed for Cell II $\left(\psi=90^{\circ}\right.$, $\psi_{0}=45^{\circ}$ and $\left.\Psi=90^{\circ}\right)$ and especially for III $(\psi=0$, $\psi_{0}=45^{\circ}$ and $\Psi=90^{\circ}$ ) which are different from the normal TN cell (Cell I). In figure 4, a distinct VCCF is

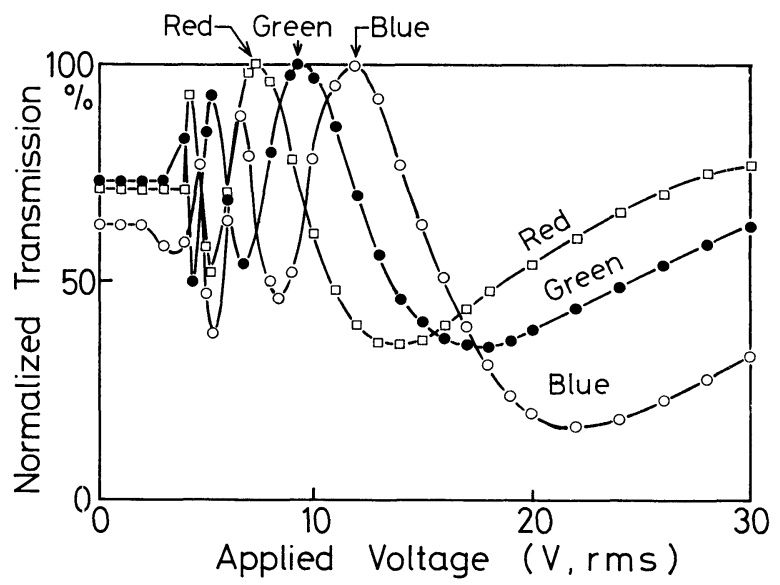

Fig. 4. - Voltage controllable color formation under the optimum condition : (zero twist angle $(\psi=0)$, crossed polarizer was set as to be $\psi_{0}$ was $45^{\circ}$ ). Measurement was made at $25^{\circ} \mathrm{C}$ on a 4: 1 mixture of MBBA and BBCA. Thickness of the cell was $9 \mu \mathrm{m}$. Applied voltage was at $5 \mathrm{kHz}$ a. c. in r. m. $\mathrm{s}$.

shown using Cell III in which angular relations were chosen so as to realize optimum condition for VCCF mentioned in the previous section. The finite values of transmission of three different lights at zero field recognized in figure 4 is originated from non-zero values of the second term in eq. (1), even though, the first term is zero. Several peaks are recognized in figure 4 according to the difference in the order of interference which is determined by the condition that $\pi \Delta n d / \lambda_{\max }=(\pi / 2)(2 m-1)$, where $m$ is an integer. 
The spectral transmission of Cell II ( $90^{\circ}$ twist) and Cell III (zero degree twist) is shown in figures 5 and 6 , respectively. The values of voltages written in these figures are applied voltage in order to get correspond-

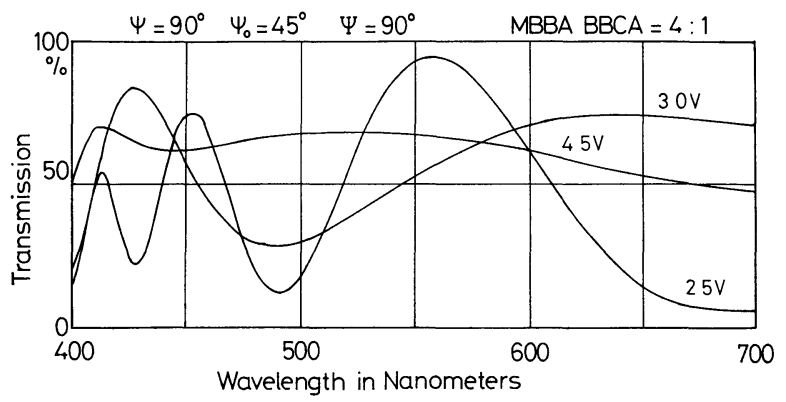

Fig. 5. - Spectra of the voltage controllable color formation under the condition $\psi=90^{\circ}, \Psi=90^{\circ}$, and $\psi_{0}=45^{\circ}$ measured at $25^{\circ} \mathrm{C}$ on a mixture of MBBA and BBCA by $4: 1$. Thickness of the cell was $9 \mu \mathrm{m}$. Applied voltage was at $5 \mathrm{kHz}$ a. c. in r. m. s.

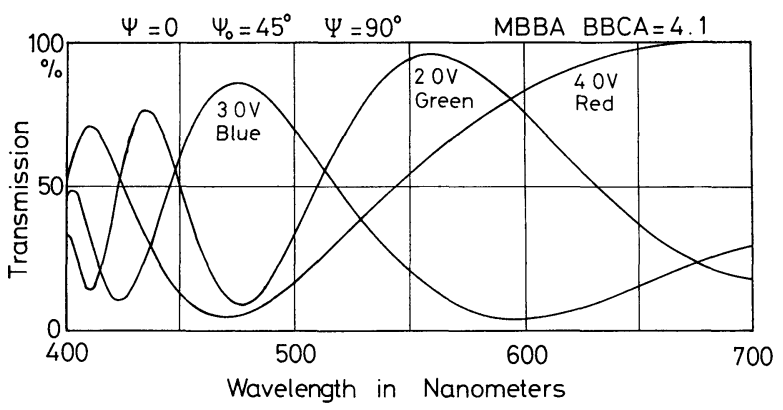

FIG. 6. - Spectra of the voltage controllable color formation under the optimum condition $\left(\psi=0, \Psi=90^{\circ}, \psi_{0}=45^{\circ}\right)$ measured at $25^{\circ} \mathrm{C}$ on a mixture of MBBA and BBCA by $4: 1$. Thickness of the cell was $9 \mu \mathrm{m}$. Applied voltage was at $5 \mathrm{kHz}$ a. c. in r. m. s.

ing three colors. A color formation is also realized using Cell II, however, significant backgrounds in the spectra are recognized in figure 5 especially when higher voltages are applied and further more, widths of the spectra become wider at higher voltages. On the other hand, the spectra shown in figure 6 on Cell III have narrower widths and fewer backgrounds when compared to those of figure 5. It is shown that at the optimum condition (Cell III) the purest color spectra can be obtained.

Occurrence of many peaks recognized in figures 5 and 6 is explained again by considering the difference in the order of the interference.

Variation of the widths with wavelength recognized in figures 5 and 6 is explained by the dependence of the width both on the peak wavelength $\lambda_{\max }$ and the birefringence $\Delta n$ which is also dependent on the wavelength as given by eq. (7).

Some amount of background is recognized in figure 6 ; the origin of which may be explained by taking into account the contribution of the absorption to the complex refractive index.

As considered in the previous section, the widths of the spectra are functions of the effective birefringence $\Delta n$. Widths of the same spectra taken from figure 6 is tabulated in Table II and are compared with calculated

\section{TABLE II}

\begin{tabular}{|c|c|c|}
\hline$\lambda \max$ & $\begin{array}{l}\text { Halfwidth } \\
\text { from eq. (8) }\end{array}$ & $\begin{array}{l}\text { Halfwidth } \\
\text { from Fig. } 6\end{array}$ \\
\hline $561 \mathrm{~nm}$ & $109.7 \mathrm{~nm}$ & $112 \mathrm{~nm}$ \\
\hline $476 \mathrm{~nm}$ & $74.3 \mathrm{~nm}$ & $80 \mathrm{~nm}$ \\
\hline
\end{tabular}

widths using eq. (8) where the used values of the birefringence were determined by measuring and analyzing the variation of the interferograms with the wavelengths caused by the multiple reflections which occured within the liquid crystal panel.

Agreement of the widths determined by the two independent methods is fairly good within experimental error. This may show the validity of the theoretical considerations given in the previous section.

4. Conclusions. - The optimum condition for the voltage controllable color formation (VCCF) using nematic liquid crystals with a positive dielectric anisotropy aligned homogeneously (molecules are parallel to the electrodes) is shown to be realized by choosing the twisting angle equal to zero and by setting the parallel or crossed polarizers at $45^{\circ}$ relative to the directors of the molecules of the liquid crystals. There are several alternative conditions for VCCF given.

The magnitudes of the spectral widths of color formation are shown to be dependent on the effective birefringences experimentally and these are compared with the widths calculated by an independent method. Agreement between them is fairly good within experimental error.

Acknowledgement. - We wish to express our gratitude to Prof. Shimazu for the use of Spectrophotometer.

\section{References}

[1] Heilmer, G. H. and Zanoni, L. A., Appl. Phys. Lett. 13 (1968) 91.

[2] Shiekel, M. F. and Fahrenschon, K., Appl. Phys. Lett. 19 (1971) 391.
[3] Assouline, G., HaRenG, M., Leiba, E. and Roncillat, M., Electron. Lett. 8 (1972) 45.

[4] Greubel, W., KrüGer, H. and Wolff, U., SiemensZ. 46 (1972) 862. 
[5] SCheffer, T. J., J. Appl. Phys. 44 (1973) 4799.

[6] Kobayashi, S. and Takeuchi, F., 1973, SID Intern. Symp., May 15-17, 1973, New York, Digest of Technical Papers p. 40 ; Proceedings of the SID, 1973, 14/4 115.

[7] Assouline, G., Hareng, M. and Leiba, E., Electron. Lett. 7 (1971) 699.

[8] Schadt, M. and Helfrich, W., Appl. Phys. Lett. 18 (1971) 127.

[9] Kobayashi, S., Takeuchi, F. and Shimomura, T., Proceedings of the 5th Conference on Solid State Devices,
Aug. 29-31, 1973, Tokyo, Supplement of J. Japan Soc. Appl. Phys. 43 (1973) 131;

Kobayashi, S. and Shimomura, T., in the press in Pramana (India) as the Proceedings of International Conference on Liquid Crystals, Dec. 3-8, 1973, Bangalore.

[10] For example VALASEK, J., Introduction to Theoretical and Experimental Optics (John Willy \& Sons Inc., New York, London) 1960, Chapter 12.

[11] LesLIE, F. M., Molecular Crystals and Liquid Crystals 12 (1970) 57.

[12] De VRIES, H., Acta Cryst. 4 (1951) 219. 